\title{
Consumer Perceptions of Online Produce Purchases
}

\author{
Carson Ostrum ${ }^{1} \&$ Adam Watson ${ }^{2}$ \\ ${ }^{1}$ Undergraduate student (Agricultural Operations Management), Agricultural \& Biological Engineering, \\ ${ }^{2}$ Assistant Professor, Agricultural and Biological Engineering, University of Florida
}

Faculty Mentor: Adam Watson, Department of Agricultural and Biological Engineering

\begin{abstract}
In the Spring of 2021, a survey of college students' perceptions and behaviors regarding grocery shopping methods, including online purchases of fresh produce, in the post-response to COVID-19 was conducted. The purpose of this research was to analyze the perceptions of online grocery shopping and identify specific factors that significantly influenced the grocery shopping experience. A sample of 203 responses was collected from undergraduate and graduate students within the College of Agricultural \& Life Sciences (CALS) at the University of Florida. Participants perceived in-store grocery shopping as superior in terms of product quality, shopping experience, store loyalty, and hygiene while convenience was perceived as an advantage with online grocery shopping. Participants identified product quality and greater transparency regarding food handling as important concerns and factors when purchasing fresh produce online. Although COVID-19 pandemic caused students to explore various online grocery services, it had limited effect on their purchasing of fresh produce. The implications for this study are far reaching, applicable to industry retailers interested in consumer willingness to pay for online grocery options and in identifying value-adding services that would increase consumer participation. This study also provides baseline data useful to researchers interested in consumer behavior, acceptance, and food marketing.
\end{abstract}

Keywords: Online grocery shopping, fresh produce, consumer perceptions and behaviors, grocery shopping preferences, COVID-19

\section{Introduction}

Early estimates for online grocery sales for 2020 were expected to continue their gradual increase within the total grocery market. However, the COVID-19 pandemic, which saw its first case in the United States in January 2020, caused a dramatic rise in online grocery shopping as food retailers' experienced more than a 300\% increase in online food sales (Redman, 2020). Market research now suggests that online grocery shopping will make up more than $21 \%$ of total grocery sales by 2025 , which equates to nearly $\$ 250$ billion (Mercatus, 2020). With that being 
said, the traditional brick-and-mortar grocery industry is being forced to adapt, and so it is important for companies to better understand how consumers feel about this societal shift towards online shopping. According to research, two of the most influential factors affecting the grocery industry today are health and convenience (He et al., 2019). This research will not only identify the perceptions associated with online fresh produce shopping, but it will also focus on determining what factors influence consumers to grocery shop in-store versus online.

The question as to whether online grocery shopping services will take off similarly to online retail shopping or if traditional grocery shopping methods will continue to dominate the market is still yet to be determined. The Millennial-aged generation has been found to care less about shopping at traditional grocery stores as they are more concerned with finding specific items (Peregrin, 2015). While we predict this mindset will cause young consumers to be more accepting of purchasing their groceries online, we expect the majority of consumers will still prefer to purchase their groceries in-person themselves. Our research will include a survey that aims to understand what young consumers value within a grocery shopping experience, their perceptions of online grocery shopping in general, and their comfortability with purchasing fresh produce through online grocery shopping services.

\section{Literature Review}

Previous studies related to online grocery shopping have been used to identify consumer habits and behavior, while others have been focused on what motivates consumers to explore online grocery shopping services (Pitts et al., 2018). From the available research, convenience was found to be one of the most influential motivations regarding online grocery shopping and consumers between the ages of 15 and 34, Millennials and Generation Z, were found to use online grocery shopping methods the most frequently (The Nielson Group, 2019). Additional advantages perceived with online grocery shopping are a wider variety of product options and the opportunity to find the best prices (Harris et al., 2017).

There are also many disadvantages associated with online grocery shopping that many consumers feel are too important to overlook. Consumers believe that the inability to judge product quality, the perceived complexity, and the lack of social interactions are what make online grocery shopping inferior to the traditional grocery shopping experience (Harris et al., 2017). However, the COVID-19 pandemic dramatically changed the way consumers all over the 
world shop for groceries and the long-term effects on the industry are yet to be determined, so it will be interesting to see if consumer perceptions of online grocery shopping change as a result (Hobbs, 2020).

A study by Dominici et al. (2021) stresses the importance of socio-demographic factors on consumer grocery shopping behavior and how certain situational influences can cause consumers to alter their grocery shopping methods altogether. For instance, having a baby or dealing with unexpected health problems are significant life events that could cause a consumer to start shopping for groceries online while consistent online grocery shoppers tend to be young, welleducated women with a strong economic standing. However, it was common for respondents to label online grocery shopping as an unreliable chore due to orders consistently being incomplete, which caused nearly all respondents who tried online methods to continue shopping in traditional grocery stores once their lives returned to normal (Hand et al., 2009).

The COVID-19 pandemic has the potential to permanently alter the grocery shopping industry as it has caused major disruptions to the way in which consumers select, purchase, and consume their food (Martin-Neuninger \& Ruby, 2020). Limitations on social interactions within grocery stores to reduce the spread of the virus take away from the fun and pleasant atmosphere associated with a traditional grocery shopping experience. This concern for health and safety has also caused an increase in grocery retailers implementing online grocery services such as contactless and curbside delivery (Martin-Neuninger \& Ruby, 2020).

\section{Materials \& Methods}

\section{Design of the Study}

The purpose of this research was to analyze the perceptions of online grocery shopping and identify specific factors that significantly influenced the grocery shopping experience. In the Fall of 2020, an online survey was developed by researchers within the College of Agricultural \& Life Sciences (CALS) at the University of Florida. The survey included multiple choice and Likert type questions and was available from January $15^{\text {th }}$ to February $5^{\text {th }}, 2021$. The target population consisted of undergraduate, graduate, and post-graduate students enrolled in CALS. The survey was designed to gather responses on how young consumers perceive the concept of purchasing fresh produce through online grocery services as well as how the COVID-19 pandemic affected their grocery shopping habits. It is hypothesized that while young consumers 
will be openly optimistic about purchasing fresh produce online, the majority will still prefer selecting their own fresh produce in the traditional grocery store setting. The objectives for this research study are to:

1. Assess young consumers (i.e., college students) attitudes and behaviors to determine factors that influence perceptions of purchasing fresh produce online

2. Explain factors that influence young consumers when it comes to their online produce shopping habits and decisions

3. Identify the level to which the COVID-19 pandemic has impacted young consumers' online produce purchasing and consumption habits

\section{Instrument of the Study}

An anonymous, online survey was designed and developed with the Qualtrics survey software. After careful revisions, the survey was then reviewed by the Institutional Review Board (IRB) and approved with exempt status (IRB ID \# 202002918) on January 13 ${ }^{\text {th }}$, 2021. All participants were provided with a statement of informed consent before agreeing to complete the survey. With permission from the UF CALS Advising Council, the survey and promotional flyer were distributed to students by academic advisors in various CALS departments.

The survey consisted of 30 questions that were categorized into general grocery shopping habits, online purchasing of fresh produce, COVID-19 impacts, and demographic sections. The survey also included two screening questions to ensure that all participants were over the age of 18 and current students at UF. The question types within the survey consisted of multiple choice (select only one choice as well as select all that apply) and ordinal feedback questions with a 5point Likert scale (where $1=$ "unimportant" and 5 = "important").

\section{Sampling Method}

A nonprobability convenience sampling strategy was implemented to the 6,519 students enrolled in CALS at UF. Researchers were not granted direct access to student contact information directly and thus were not able to know exactly how many students received the survey; however, our request for the UF CALS Advising Council to distribute our survey to the various department academic advisors and respective department listservs was approved. The survey was distributed through the CALS Advising Council on January 15, 2021, although some 
departments may not have been able or willing to distribute the survey. Still, there were 240 participants from various departments and at different levels (i.e., undergraduate and graduate). The convenience sampling method was chosen because it was prompt, uncomplicated, and economical.

\section{Data Analysis}

The survey data were analyzed using SPSS Statistics 26 and Microsoft Excel where descriptive statistics and measures of central tendency were calculated and reported. Cross tabulation tables were constructed to compare differences of participants for select variables. Paired sample t-tests were used to compare the mean differences between in-store and online grocery shopping factors. Mean and standard deviation of important factors for in-person and online fresh produce shopping in addition to count, cumulative percentages, and frequencies were calculated, analyzed, and reported.

\section{Results \& Discussion}

\section{Demographics of participants}

A total of 240 participants began the survey, but after cleaning and removing responses for participants that did not meet screening requirements (at least 18 years of age and a current student at UF), only 203 responses were used for analysis. A breakdown of the participant sample based on gender, age, occupational status, and student classification can be found in Table 1.

Table 1. Summary of demographic variables

\begin{tabular}{llcc}
\hline Variable & Response & Count & Percent \% \\
\hline Gender & Male & 52 & $30.8 \%$ \\
& Female & 109 & $64.5 \%$ \\
& Prefer not to say & 8 & $4.7 \%$ \\
Age & $18-19$ & 9 & $5.5 \%$ \\
& $20-21$ & 49 & $29.7 \%$ \\
& $22-25$ & 38 & $23.0 \%$ \\
& $26-30$ & 33 & $20.0 \%$ \\
& $31-40$ & 28 & $17.0 \%$ \\
Occupational Status & $40+$ & 8 & $4.8 \%$ \\
& Full-time student & 94 & $56.0 \%$ \\
& Part-time student & 1 & $0.6 \%$
\end{tabular}




\begin{tabular}{|l|c|cc}
\hline & Full-time student and work & 43 & $25.6 \%$ \\
& Part-time student and work & 23 & $13.7 \%$ \\
& Prefer not to say & 0 & $0.0 \%$ \\
& Other & 7 & $4.2 \%$ \\
\hline \multirow{3}{*}{ Student Classification } & Freshman & 2 & $1.2 \%$ \\
& Sophomore & 15 & $8.9 \%$ \\
& Junior & 35 & $20.7 \%$ \\
& Senior & 29 & $17.2 \%$ \\
& Fifth year & 5 & $3.0 \%$ \\
& Graduate Student & 40 & $23.7 \%$ \\
& Ph.D. graduate student & 41 & $24.3 \%$ \\
& Faculty & 2 & $1.2 \%$ \\
\hline
\end{tabular}

\section{General grocery purchasing habits}

Participants were asked an initial series of questions regarding their general grocery shopping habits. The responses indicated that most participants were relatively new to grocery shopping for themselves and that they normally shop at Publix Super Markets once a week. A more indepth breakdown of their general grocery shopping habits can be found in Table 2.

Table 2. General grocery shopping habits

\begin{tabular}{llcc}
\hline Question & Response & Count & Percent \% \\
\hline $\begin{array}{l}\text { Are you the primary grocery } \\
\text { shopper for where you }\end{array}$ & Yes & 178 & $87.7 \%$ \\
currently live? & No & 25 & $12.3 \%$ \\
How long have you been the & Less than a year & & \\
primary grocery shopper for & 1 - 2 years & 29 & $17.9 \%$ \\
where you currently live? & 3 - 4 years & 38 & $23.5 \%$ \\
& More than 4 years & 43 & $26.5 \%$ \\
& Other & 51 & $31.5 \%$ \\
How frequently do you shop & Every day & 1 & $0.6 \%$ \\
for grocery items? & Several times a week & 0 & $0.0 \%$ \\
& Once per week & 33 & $17.9 \%$ \\
& Less than once per week & 36 & $60.3 \%$ \\
& Other & 4 & $19.6 \%$ \\
& Publix & 81 & $44.0 \%$ \\
& Winn-Dixie & 5 & $2.7 \%$
\end{tabular}




\begin{tabular}{llcc} 
What store/business do you & Whole Food's & 7 & $3.8 \%$ \\
normally purchase your & Aldi & 22 & $12.0 \%$ \\
grocery items from? & Trader Joe's & 12 & $6.5 \%$ \\
& Walmart & 30 & $16.3 \%$ \\
& Other & 27 & $14.7 \%$ \\
\hline
\end{tabular}

To better understand consumer behavior regarding general grocery shopping preferences, participants were asked to indicate which factors influenced their decision on where to shop for groceries. The three most influential factors by far were price, convenient location/proximity, and product quality as they were selected by $28 \%, 27 \%$, and $25 \%$ of the participants respectively (Table 3). Additionally, approximately 33\% of participants stated that they purchase groceries online while $67 \%$ indicated that they do not. The survey results indicate that consumers who use online grocery shopping services are more likely to be concerned with product quality issues, while those that purchase groceries in-person are more concerned with price, and that the ordering of these factors reflects key differences in consumers' priorities.

Table 3. Influential factors of grocery shopping

\begin{tabular}{lcccc}
\hline Participants purchase groceries online? & \multicolumn{2}{c}{ Yes } & \multicolumn{2}{c}{ No } \\
\hline Influential factors & Count & Percent & Count & Percent \\
Price & 15 & $25 \%$ & 37 & $30 \%$ \\
Product Quality & 21 & $34 \%$ & 24 & $20 \%$ \\
Product Selection/Variety & 6 & $10 \%$ & 15 & $12 \%$ \\
Customer Service & 2 & $3 \%$ & 2 & $2 \%$ \\
Convenient Location/Proximity & 14 & $23 \%$ & 36 & $29 \%$ \\
Online Ordering Availability & 2 & $3 \%$ & 0 & $0 \%$ \\
Other & 1 & $2 \%$ & 9 & $7 \%$ \\
Total & 61 & $100 \%$ & 123 & $100 \%$ \\
\hline
\end{tabular}

\section{Online fresh produce purchases}

When asked about their general interest in purchasing fresh produce online, most participants were not interested with $28 \%$ stating they are slightly uninterested and more than $29 \%$ being very uninterested. Even though $27 \%$ of participants indicated they were slightly interested in the idea of purchasing fresh produce online, only $16 \%$ were very interested in the idea. We find the 
differences at the extreme values to be quite telling of our participants' perception of purchasing fresh produce online as there appears to be a much stronger negative perception of the idea from our sample.

Approximately $33 \%$ of participants indicated they purchased fresh produce while shopping for groceries online and when asked about their overall experience, $77 \%$ of those participants expressed that they were either moderately or extremely satisfied. Survey data show that "quality preference options" and "better transparency regarding food handling" were the two most important elements as they were selected by $51 \%$ and $43 \%$ of all participants (Table 4 ). Additionally, $70 \%$ of participants identified "poor product quality" and $49 \%$ of participants indicated that the "inability to inspect products in person" would discourage them from purchasing fresh produce online. This shows that factors related to product quality and safe food handling are a top priority for online fresh produce purchasing.

Table 4. Important factors for purchasing fresh produce online

\begin{tabular}{llcc}
\hline Question & Response & Count & Percent \% \\
\hline What improvements could be & Quality preference options & 104 & $51.2 \%$ \\
$\begin{array}{l}\text { made to enhance the experience of } \\
\text { purchasing fresh produce online? }\end{array}$ & Better transparency regarding food & 88 & $43.3 \%$ \\
& handling & & $70.4 \%$ \\
& Poor product quality & 143 & $49.3 \%$ \\
& Inability to inspect products in & 100 & \\
& person & & \\
\hline
\end{tabular}

Participants were asked to rate factors related to the online purchasing of fresh produce on a 5point Likert scale ( $1=$ "unimportant" and $5=$ "important"). Participants once again highlighted "product quality" and "hygiene/cleanliness" as the most important elements as seen in Table 5 which summarizes the means and standard deviations of important factors related to online fresh produce shopping.

Table 5. Mean and standard deviation of important factors of online fresh produce shopping

\begin{tabular}{lll}
\hline Factors & Mean Std. Deviation \\
\hline
\end{tabular}




\begin{tabular}{lcc}
\hline Convenience & 4.22 & 1.154 \\
Price & 4.27 & 0.953 \\
Product Quality & 4.72 & 0.606 \\
Product Variety & 4.05 & 1.016 \\
Shopping Experience/Environment & 3.25 & 1.282 \\
Store Loyalty & 2.23 & 1.182 \\
Hygiene/Cleanliness & 4.34 & 1.004 \\
Brand Loyalty & 2.21 & 1.277 \\
\hline
\end{tabular}

To gain a better understanding of why consumers may be hesitant to purchase fresh produce online, participants were asked to choose from a list of concerns associated with online fresh produce shopping. By far the most common reason was ripeness preferences as $47 \%$ of participants have concerns regarding the level of ripeness they will receive through online grocery shopping services (Figure 1). The second most common response was also related to quality concerns as $30 \%$ of participants feared they would receive damaged fresh produce. However, approximately $36 \%$ of participants indicated that they "enjoy the experience of physically going grocery shopping" which suggests that the sensory experience of shopping inperson is still an important reason why consumers do not purchase food items online. Our prediction was that younger consumers, those within the Gen $\mathrm{Z}$ or Millennial generation, would care less about the physical experience of a grocery shopping trip due to their familiarity with online services and technology in general, but perhaps the traditional grocery shopping experience transcends age groups and technological innovation. 


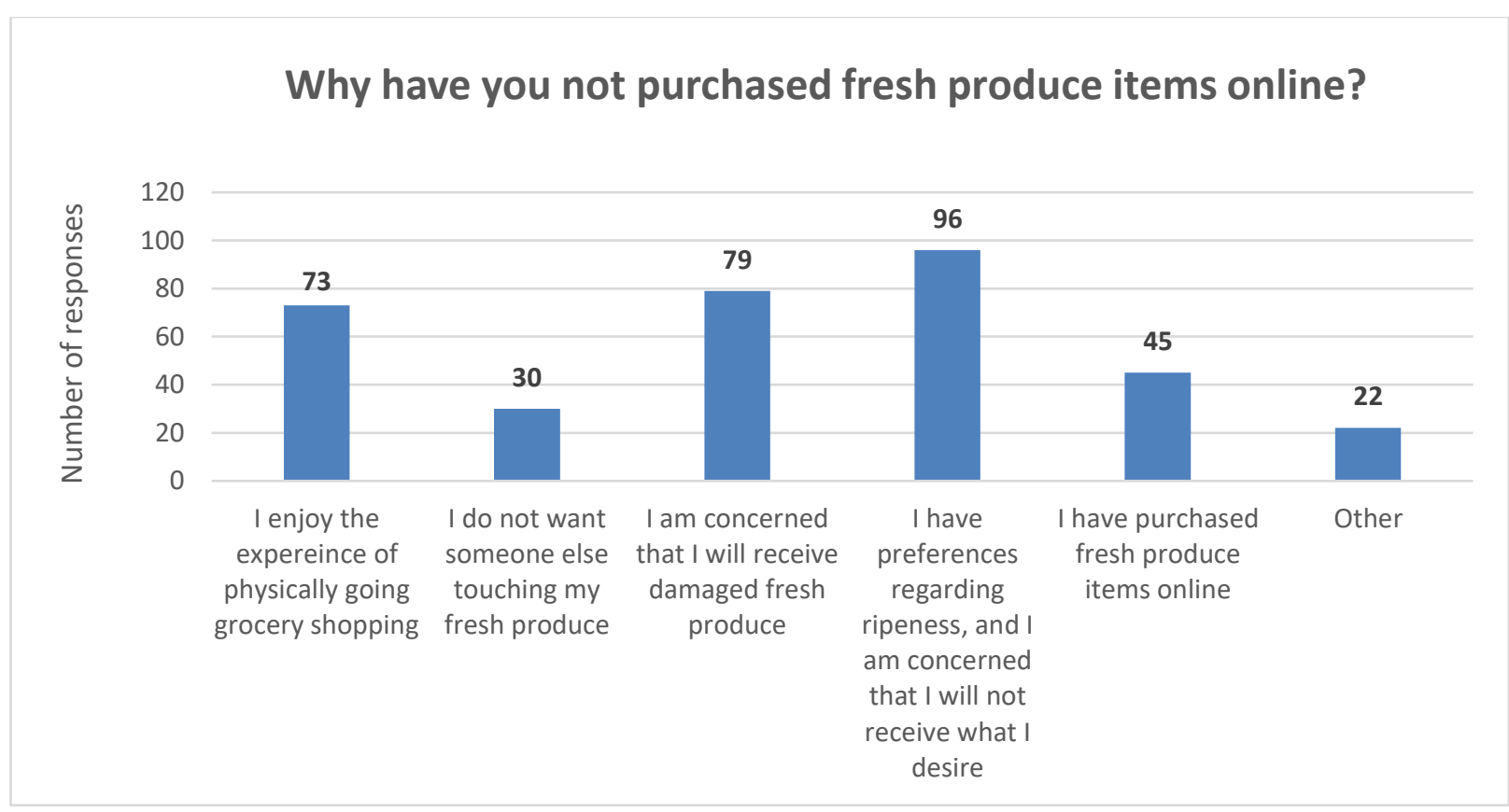

Figure 1. Summary of participant responses for why they have not purchased fresh produce items online

We conducted a paired sample t-test for 10 paired Likert-type items (Table 6). Convenience was found to be greater for online grocery purchases $(p=0.012)$ with a mean difference of -0.284 . This was unsurprising given that online grocery purchases are more convenient for reasons such as hands-free shopping and personal delivery options. The mean difference for product quality was positive and statistically significant $(p=0.04)$, indicating that participants perceived the quality of in-store grocery purchases as being superior. The mean difference for hygiene/cleanliness was 0.863 and statistically significant $(p=0.000)$, indicating that participants perceived in-store grocery shopping as the cleaner method for purchasing groceries. This was surprising because online grocery services should be just as hygienic as in-store grocery shopping if not even more so. We speculate that consumers view online grocery services as an additional point of potential contamination as people are usually very risk adverse with respect to who handles their food. Grocery retailers may need to be more transparent about their food handling practices and advertise the safety precautions they have in place for their online grocery shopping services. 
Table 6. Mean difference between in-store and online grocery shopping factors

\begin{tabular}{|c|c|c|c|c|c|c|c|c|}
\hline & \multirow[b]{2}{*}{$\begin{array}{c}\text { Mean } \\
\text { Diff. }\end{array}$} & \multirow[b]{2}{*}{$\begin{array}{l}\text { Std. } \\
\text { Dev. }\end{array}$} & \multirow[b]{2}{*}{$\begin{array}{l}\text { Std. } \\
\text { Error }\end{array}$} & \multicolumn{2}{|c|}{$\begin{array}{l}\text { 95\% Confidence } \\
\text { Interval of the } \\
\text { Difference }\end{array}$} & \multirow[b]{2}{*}{$\mathbf{t}$} & \multirow[b]{2}{*}{ df } & \multirow[b]{2}{*}{$\begin{array}{c}\text { Sig. } \\
\text { (2-tailed) }\end{array}$} \\
\hline & & & & Lower & Upper & & & \\
\hline Convenience & -0.284 & 1.507 & 0.111 & -0.504 & -0.064 & -2.551 & 182 & $* * 0.012$ \\
\hline Price & 0.049 & 1.159 & 0.086 & -0.120 & 0.218 & 0.574 & 182 & 0.567 \\
\hline Product Quality & 0.219 & 1.025 & 0.076 & 0.069 & 0.368 & 2.884 & 182 & $* * * 0.004$ \\
\hline $\begin{array}{l}\text { Product Selection/Variety } \\
\text { Shopping }\end{array}$ & -0.055 & 1.221 & 0.090 & -0.233 & 0.123 & -0.605 & 182 & 0.546 \\
\hline Experience/Environment & 0.454 & 1.568 & 0.116 & 0.225 & 0.682 & 3.913 & 182 & $* * * 0.000$ \\
\hline $\begin{array}{l}\text { Store Loyalty } \\
\text { Selecting Products in }\end{array}$ & 0.273 & 1.214 & 0.090 & 0.096 & 0.450 & 3.044 & 182 & $* * * 0.003$ \\
\hline Person & 1.082 & 1.475 & 0.109 & 0.867 & 1.297 & 9.926 & 182 & $* * * 0.000$ \\
\hline Hygiene/Cleanliness & 0.863 & 1.417 & 0.105 & 0.657 & 1.070 & 8.241 & 182 & $* * * 0.000$ \\
\hline Brand Loyalty & 0.082 & 0.949 & 0.070 & -0.056 & 0.220 & 1.169 & 182 & 0.244 \\
\hline Packaging/Presentation & -0.109 & 1.063 & 0.079 & -0.264 & 0.046 & -1.390 & 182 & 0.166 \\
\hline
\end{tabular}

\section{Impacts of COVID-19 on fresh produce purchases}

In an attempt to better understand how the COVID-19 pandemic affected the way consumers purchase groceries, participants were asked a series of questions related to their grocery shopping habits before and after the COVID-19 pandemic (Figure 2). Approximately 19\% of participants changed their primary method of grocery shopping and more than $40 \%$ of those participants switched to online grocery shopping services. When participants were asked if their method of purchasing fresh produce had changed due to the COVID-19 pandemic, approximately $75 \%$ of participants did not change their habits as they still purchased all of their fresh produce in-person and $96 \%$ of participants indicated that they would be purchasing their fresh produce in-person once COVID-19 was no longer a concern. Based on these responses, it appears that health/safety concerns due to the COVID-19 pandemic are not severe enough to influence young consumers' purchasing behavior of fresh produce in the long run. 


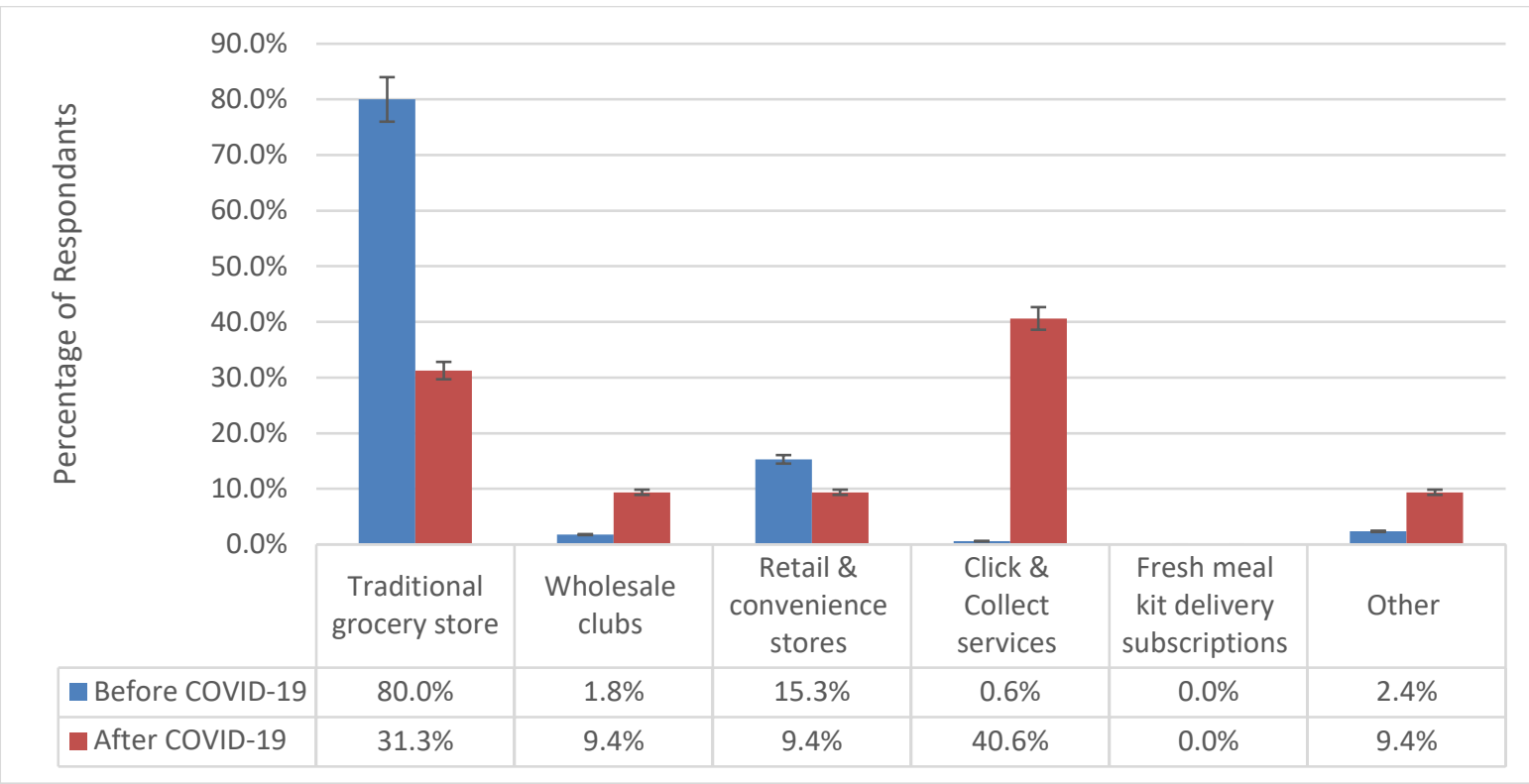

Figure 2. Summary of participants responses for their primary method of purchasing grocery items before COVID-19 ( $\mathrm{n}=170)$ and after COVID-19 ( $\mathrm{n}=32)$. Data for after COVID-19 only includes participants that indicated their grocery shopping habits were affected because of the pandemic

\section{Conclusion}

Using a survey instrument, researchers were able to study how consumer grocery shopping habits were affected by the COVID-19 pandemic as well as analyze their perceptions of purchasing fresh produce online. This study also focused on comparing in-store and online grocery shopping to determine which factors were the most influential on consumer grocery shopping behavior. It was found that participants perceived in-store grocery shopping as superior in terms of product quality, shopping experience, store loyalty, and hygiene while convenience was perceived as an advantage with online grocery shopping. While the majority of participants still shop at traditional grocery stores, the COVID-19 pandemic did cause participants to switch to online grocery shopping methods. Most participants agreed online grocery shopping would become as popular as online retail shopping as $40 \%$ stated it was somewhat likely and $24 \%$ indicated it was very likely. Participants also emphasized their concerns over product quality and safety when purchasing fresh produce online, as they identified quality preference options and better transparency regarding food handling as potential improvements. The inability to select ripeness preferences along with the potential of receiving damaged products were specific concerns associated with the product quality of fresh produce purchased online. Overall, the authors hope these survey results will help grocery retailers 
identify and implement value-added services within their online grocery services to increase consumer participation as well as provide baseline data for academics interested in consumer behavior and food marketing.

\section{Acknowledgements}

We would like to thank the CALS Advising Council for their assistance in distributing our survey instrument and would like to especially thank Robin Snyder, Advisor of Graduate and Undergraduate Programs within the Department of Agricultural \& Biological Engineering, for her constant support throughout the research process. We would like to thank Raminder Kaur for her assistance in the survey development process and Dr. Kati Migliaccio, Professor and Chair for the Department of Agricultural \& Biological Engineering, for providing funding for this research opportunity as part of the UF ABE Undergraduate Research Scholarship. We would also like to thank the Center for Undergraduate Research at UF for providing funding and educational resources through the University Scholars Program.

\section{References}

Anesbury, Z., Nenycz-Thiel, M., Dawes, J., Kennedy, R. (2015). How do shoppers behave online? An observational study of online grocery shopping. Journal of Consumer Behaviour, 15(3), 261-270.

Benn, Y., Webb, T., Chang, B., Reidy, J. (2015). What information do consumers consider, and how do they look for it, when shopping for groceries online?. Appetite, 89, 265-273.

Campo, K. \& Breugelmans, E. (2015). Buying groceries in brick and click stores: Category allocation decisions and the moderating effect of online buying experience. Journal of Interactive Marketing, 31, 63-78.

Chang, H.-H. and Meyerhoefer, C.D. (2021), COVID-19 and the Demand for Online Food Shopping Services: Empirical Evidence from Taiwan. American Journal of Agricultural Economics.

Dominici, A., Boncinelli, F., Gerini, F., Marone, E. (2021). Determinants of online food purchasing: The impact of socio-demographic and situational factors. Journal of Retailing and Consumer Services, 60.

Elms, J., de Kervenoael, R., \& Hallsworth, A. (2016). Internet or store? An ethnographic study of consumers' internet and store-based grocery shopping practices. Journal of Retailing and Consumer Services, 32(C), 234-243.

Esbjerg, L., Jensen, B., Bech-Larsen, T., Dutra de Barcellos, M., Boztug, Y., Grunert, K. (2012). An integrative conceptual framework for analyzing customer satisfaction with shopping trip experiences in grocery retailing. Journal of Retailing and Consumer Services, 19(4), 445-456.

Hand, C., Dall'Olmo Riley, F., Harris, P., Singh, J. and Rettie, R. (2009), "Online grocery shopping: the influence of situational factors", European Journal of Marketing, 43(9), 1205-1219.

Hanus, Gabriela. (2016). Consumer Behaviour During Online Grocery Shopping. CBU International Conference Proceedings, 4. 
Harris, P., Dall'Olmo Riley, F., Riley, D. and Hand, C. (2017), "Online and store patronage: a typology of grocery shoppers", International Journal of Retail \& Distribution Management, 45(4), 419-445.

He, B., Gan, X., Yuan, K. (2019). Entry of online presale of fresh produce: A competitive analysis. European Journal of Operational Research, 272(1), 339-351.

Hobbs, Jill. (2020). Food supply chains during the COVID-19 pandemic. Canadian Journal of Agricultural Economics, 68, 171-176.

Institutional Planning \& Research - IPR (2021). Enrollment and Demographics at the University of Florida. Retrieved from https://ir.aa.ufl.edu/uffacts/enrollment-1/

Martin-Neuninger, R., \& Ruby, M. B. (2020). What Does Food Retail Research Tell Us About the Implications of Coronavirus (COVID-19) for Grocery Purchasing Habits?. Frontiers in Psychology, 11, 1448.

Mercatus. (2020) eGrocery's New Reality: The Pandemic's Lasting Impact on U.S. Grocery Shopper Behavior. Retrieved from https://www.mercatus.com/wp-content/uploads/2020/09/eGroceryShopper-Behavior-Report-by-Mercatus-and Incisiv.pdf

Namin, A. \& Dehdashti, Y. (2019). A "hidden" side of consumer grocery shopping choice, Journal of Retailing and Consumer Services, 48, 16-27.

Nielson Company (2019). Fresh and Focused: The U.S. Retailer Path to Winning Brick and Mortar. https://www.nielsen.com/us/en/insights/article/2019/fresh-and-focused-the-u-s-retailer path-towinning-brick-and-mortar/

Peregrin, Tony. (2015). Understanding millennial grocery shoppers' behavior and the role of the registered dietician nutritionist. Journal of the Academy of Nutrition and Dietetics. 115(9), 13801383.

Pitts, S., Ng, S., Blitstein, J., Gustafson, A., \& Niculescu, M. (2018). Online grocery shopping: Promise and pitfalls for healthier food and beverage purchases. Public Health Nutrition, 21(18), 33603376.

Punj, Girish. (2011). Effect of consumer beliefs on online purchase behavior: The influence of demographic characteristics and consumption values. Journal of Interactive Marketing, 25(3), 134-144.

Rogus, S., Guthrie, F., Niculescu, M., \& Mancino, L. (2019). Online grocery shopping knowledge, attitudes, and behaviors among supplemental nutrition assistance program participants. Journal of Nutrition Education and Behavior.

Redman, Russell. (2020). FMI: Online grocery sales jumped 300\% early in pandemic. https://www.supermarketnews.com/issues-trends/fmi-online-grocery-sales-jumped-300-earlypandemic

Yanzhi, L., Cheang, B., \& Lim, A. (2011). Grocery perishables management. Production and Operations Management, 21(3), 504-517. 